\title{
Gauging acceptability: the utility of a national attitudes survey toward a trial of pressure garment therapy for burns scar management
}

\author{
Susan Wright ${ }^{*}$, Laura Jones ${ }^{1}$, Naiem Moiemen²${ }^{2}$, Margaret Grant ${ }^{1}$, Jonathan Mathers ${ }^{1}$ \\ From 3rd International Clinical Trials Methodology Conference \\ Glasgow, UK. 16-17 November 2015
}

\section{Background}

Trials may be difficult to conduct due to a lack of acceptability of the trial question. For example, trials of existing treatments that are established in routine clinical practice without robust supporting evidence might be undermined by a lack of acceptability or presumed difficulty in recruiting patients. The NIHR HTA commissioned a feasibility study of pressure garment therapy for burns scar management as it was thought a full-scale trial would be difficult to conduct.

\section{Methods}

Pegasus is the resulting commissioned mixed-methods feasibility study which consists of an external pilot trial with process evaluation. To gauge acceptability, in addition to the pilot, we conducted a national survey of attitudes towards a full-scale trial amongst the burns clinical community, supplemented by telephone interviews $(\mathrm{n}=15)$.

\section{Findings}

Staff in 27 of $29(\mathrm{n}=223)$ surveyed burns services responded. Although a majority $(67 \%)$ were in favour of a trial, this headline figure hides a more complex picture, particularly, in relation to clinical equipoise around the trial question. This has clear implications for the conduct of a national trial. We were able to further explore these survey findings via the telephone interviews and with emerging observations from the pilot trial and process evaluation.

\section{Discussion}

We discuss the utility of conducting a national survey of attitudes in addition to a pilot trial amongst a smaller sample of burns services. We reflect on whether this approach may provide insights over and above those identified from a small scale feasibility pilot.

\section{Authors' details \\ 'University of Birmingham, Birmingham, West Midlands, UK. ${ }^{2}$ University Hospitals Birmingham, Birmingham, West Midlands, UK.}

Published: 16 November 2015

doi:10.1186/1745-6215-16-S2-P21

Cite this article as: Wright et al: Gauging acceptability: the utility of a national attitudes survey toward a trial of pressure garment therapy for burns scar management. Trials 2015 16(Suppl 2):P21.

\section{Submit your next manuscript to BioMed Central and take full advantage of: \\ - Convenient online submission \\ - Thorough peer review \\ - No space constraints or color figure charges \\ - Immediate publication on acceptance \\ - Inclusion in PubMed, CAS, Scopus and Google Scholar \\ - Research which is freely available for redistribution \\ Submit your manuscript at www.biomedcentral.com/submit}

